九州大学学術情報リポジトリ

Kyushu University Institutional Repository

\title{
Exponential Function, Bondi K-Factor and Imaginary Unit
}

Shimojo, Masataka

Laboratory of Regulation in Metabolism and Behavior, Division of Animal and Marine Bioresource

Sciences, Department of Bioresource Sciences, Faculty of Agriculture, Kyushu University

https://doi.org/10.5109/20322

出版情報: 九州大学大学院農学研究院紀要. 56 (2)，pp.285-286，2011-09. Faculty of Agriculture， Kyushu University

バージョン :

権利関係 : 


\title{
Exponential Function, Bondi K-Factor and Imaginary Unit
}

\author{
Masataka SHIMOJO* \\ Laboratory of Regulation in Metabolism and Behavior, Division of Animal and Marine Bioresource Sciences, \\ Department of Bioresource Sciences, Faculty of Agriculture, \\ Kyushu University, Fukuoka 812-8581, Japan \\ (Received April 28, 2011 and accepted May 9, 2011)
}

\begin{abstract}
The growth of a plant or an animal is analyzed using the exponential function. This study was designed to investigate mathematical properties of the exponential function using relationships between the exponential function, the Bondi $\mathrm{K}$-factor and the imaginary unit. The results obtained were as follows. The exponential function was equal to the Bondi $\mathrm{K}$-factor. When the Bondi $\mathrm{K}$-factor took the value greater than 1 , there occurred an exponential increase. This implied an association with the phenomenon that ingesting energy and substances from the environment caused the increase in size and weight of a plant or an animal. The mathematical operation of $v \rightarrow \infty$ caused the collapse of the Bondi K-factor into the imaginary unit. This collapse left a gap between the imaginary unit and the exponential function. There was also a discussion on the relationship between the object with the Bondi $\mathrm{K}$-factor and the wave function described using complex numbers. It was suggested that mathematical properties of the exponential function were related to those of the Bondi K-factor.
\end{abstract}

\section{INTRODUCTION}

The basic growth analysis of a plant (Blackman, 1919) or an animal (Brody, 1945) is conducted using the exponential function. I have been interested in mathematical aspects of the exponential function, from the viewpoint of symmetric properties with respect to its differential and integral calculations (Shimojo et al., 2002) and relationships to the hyperbolic function and the Euler's formula (Shimojo et al., 2003). Shimojo (2011) reported the equality between the exponential function and the Bondi $\mathrm{K}$-factor by relating the hyperbolic function to both the exponential function and the Lorentz transformation. The translator's afterword to the book by Bondi (1964) showed the relationship between the Bondi $\mathrm{K}$-factor and the exponential function. In addition, there was a collapse of the Bondi K-factor into the imaginary unit when $v$ (velocity of an object) $\rightarrow \infty$ (Shimojo, 2011). These two issues of my concern remain to be investigated, because the Bondi $\mathrm{K}$-factor has been considered an educational tool for teaching the special relativity to students (Dasgupta, 2007).

The present study was designed to investigate mathematical properties of the exponential function using relationships between the exponential function, the Bondi $\mathrm{K}$-factor and the imaginary unit.

\section{MATHEMATICAL RELATIONSHIPS BETWEEN EXPONENTIAL FUNCTION, BONDI K-FACTOR AND IMAGINARY UNIT}

\section{Exponential function and Bondi K-factor}

Relating the hyperbolic function to both the exponential function and the Lorentz transformation gives

\footnotetext{
* Corresponding author (E-mail: mshimojo@agr.kyushu-u.ac.jp)
}

$$
\begin{aligned}
\cosh (\theta) & =(\exp (\theta)+\exp (-\theta)) / 2 \\
= & 1 / \sqrt{1-(v / c)^{2},} \\
\sinh (\theta) & =(\exp (\theta)-\exp (-\theta)) / 2 \\
& =(v / c) / \sqrt{1-(v / c)^{2}},
\end{aligned}
$$

where $v=$ velocity of an object, $c=$ speed of light.

Solving functions (1) and (2) gives

$$
\begin{aligned}
& \exp (\theta)=\sqrt{(1+v / c) /(1-v / c)}, \\
& \exp (-\theta)=\sqrt{(1-v / c) /(1+v / c)}, \\
& \theta=\log _{\mathbf{e}}(\sqrt{(1+v / c) /(1-v / c)}), \\
& v=c \cdot(\exp (2 \theta)-1) /(\exp (2 \theta)+1),
\end{aligned}
$$

where $0 \leq v<c, 0 \leq \theta<\infty, 1 \leq \exp (\theta)<\infty, 0<$ $\exp (-\theta) \leq 1$.

Functions (3-1) (3-4) show or imply the following. There is equality between $\exp (\theta)$ and the Bondi $\mathrm{K}$-factor as shown in (3-1). When $v$ takes a constant value in $0<v<c$, there occurs an exponential increase. When there is an increase in $v$, the rate at which $\theta$ increases is accelerated. If $\exp (\theta)$ is assumed to show the property of space, then the existence of energy $(v)$ implies the space expansion with time $(t)$ when applied to $\exp (\theta \cdot t)$. This also applies to the growth of a plant or an animal, where ingesting energy and substances from the environment causes the increase in size and weight of them. Thus, relative growth rate $(r)$ in the basic growth function (4) for a plant or an animal implies the correspondence to $\theta$ in the exponential function (3-1) for the special relativistic motion,

$W=W_{0} \cdot \exp (r \cdot t)$, 
where $W=$ weight of a plant or an animal, $W_{0}=$ weight at $t=0, r=$ relative growth rate.

\section{Bondi K-factor and imaginary unit}

Despite $0 \leq v<c$, the mathematical application of $v$ $\rightarrow \infty$ to the Bondi $\mathrm{K}$-factor and related items gives the following calculations. Thus,

$$
\begin{aligned}
& \lim _{v \rightarrow \infty} \sqrt{(1+v / c) /(1-v / c)}=\lim _{v \rightarrow \infty} \sqrt{(c / v+1) /(c / v-1)} \\
& =\sqrt{-1}=\boldsymbol{i}, \\
& \exp (\theta) \rightarrow \boldsymbol{i}=\exp (\boldsymbol{i}(\pi / 2)) \\
& =\cos (\pi / 2)+\boldsymbol{i} \sin (\pi / 2), \\
& \lim _{v \rightarrow \infty}\left(1 / \sqrt{1-(v / c)^{2}}\right)=\lim _{v \rightarrow \infty}\left((c / v) / \sqrt{(c / v)^{2}-1}\right) \\
& =0 \text {, } \\
& \lim _{v \rightarrow \infty}\left((v / c) / \sqrt{1-(v / c)^{2}}\right)=\lim _{v \rightarrow \infty}\left(1 / \sqrt{(c / v)^{2}-1}\right) \\
& =1 / \sqrt{-1}=-\boldsymbol{i}, \\
& c \cdot t^{\prime}=(c \cdot t) \cdot \cosh (\theta)-x \cdot \sinh (\theta) \\
& \rightarrow(c \cdot t) \cdot 0-x \cdot(-\boldsymbol{i})=\boldsymbol{i} x, \\
& x^{\prime}=x \cdot \cosh (\theta)-(c \cdot t) \cdot \sinh (\theta) \\
& \rightarrow x \cdot 0-(c \cdot t) \cdot(-\boldsymbol{i})=\boldsymbol{i}(c \cdot t), \\
& m^{\prime}=m \cdot\left(1 / \sqrt{1-(v / c)^{2}}\right) \\
& \rightarrow m \cdot 0=0 \text {. }
\end{aligned}
$$

where $\boldsymbol{i}=$ imaginary unit, $x=$ space in one dimension. Mathematical phenomena (5-1) (5-7) imply the following hypotheses. The object moving at the speed of $\infty$ is a mathematical phenomenon that is impossible to observe at any particular position. The resultant collapse of Bondi $\mathrm{K}$-factor and related items implies a mathematical trick to transform the mathematical object into a mathematical field for describing wave functions such as (6-1) and (6-2) that are also impossible to make direct observations,

$$
\begin{aligned}
& \Psi(x, t)=A \cdot \exp ((\boldsymbol{i} / \hbar) \cdot(p \cdot x-E \cdot t)), \\
& \Psi^{*}(x, t)=A \cdot \exp ((-\boldsymbol{i} / \hbar) \cdot(p \cdot x-E \cdot t)),
\end{aligned}
$$

where $\Psi=$ wave function, $\Psi^{*}=$ conjugate complex, $\hbar=$ $h / 2 \pi$ ( $h$ : Planck's constant, $\pi$ : circular constant), $A=$ amplitude, $p=$ momentum, $E$ = energy.

Then, boldly writing, the following are implied. There is no existence of the object moving at the speed of $\infty$. Instead, the wave function exists. However, if there is an observation of the object with the Bondi K-factor, then there is a disappearance of the imaginary unit and the wave function. If the object is observed at a particular position, then the Bondi $\mathrm{K}$-factor may be calculated as follows,

$$
\begin{aligned}
& (\sqrt{(1+v / c) /(1-v / c)}) \cdot(\sqrt{(1-v / c) /(1+v / c)}) \\
& =\exp (\theta) \cdot \exp (-\theta) .
\end{aligned}
$$

It is shown that any value of $\theta$ or $v$ satisfies (7). Its hypothetic correspondence in wave functions (6-1) and (6-2) is given by

$$
\Psi^{*}(x, t) \cdot \Psi(x, t)=|\Psi(x, t)|^{2}=1 .
$$

\section{Exponential function and imaginary unit}

As shown in the preceding section, there is a gap between the imaginary unit and the exponential function due to the collapse of the Bondi $\mathrm{K}$-factor. However, the disappearance of the wave function caused by the disappearance of the imaginary unit leads again to the Bondi $\mathrm{K}$-factor, an appearance of the exponential function used for the growth analysis of a plant or an animal.

\section{Conclusions}

The present study suggests that mathematical properties of the exponential function are related to those of the Bondi K-factor. All the present results and discussion will be subjected to the harsh criticism.

\section{ACKNOWLEDGEMENTS}

This study was supported by a Grant-in-Aid for Challenging Exploratory Research from Japan Society for the Promotion of Science (No. 21658089).

\section{REFERENCES}

Blackman, V. H. 1919 The compound interest law and plant growth. Ann. Bot., 33: 353-360

Bondi, H. 1964 Relativity and Common Sense (Doubleday and Company Inc.,). Translation into Japanese by T. Yamanouchi for publication (1967), Kawade Shobo Publishers, Tokyo

Brody, S. 1945 Time relations of growth of individuals and populations. In "Bioenergetics and growth - with special reference to the efficiency complex in domestic animals", Reinhold Publishing Corporation, New York, pp. 484-574

Dasgupta, A. 2007 Relativistic kinetics from the Bondi K-calculus. Eur. J. Phys., 28: 817-831

Shimojo, M., Y. Asano, K. Ikeda, R. Ishiwaka, T. Shao, H. Sato, Y. Matsufuji, N. Ohba, M. Tobisa, Y. Yano and Y. Masuda 2002 Basic growth analysis and symmetric properties of exponential function with base e. J. Fac. Agr., Kyushu Univ., 47: $55-60$

Shimojo, M., K. Ikeda, Y. Asano, R. Ishiwaka, T. Shao, H. Sato, M. Tobisa, Y. Nakano, N. Ohba, Y. Yano and Y. Masuda 2003 Exponential functions with base $e$ in growth analysis and deriving them from rotations of axes of time described using Euler's formula. J. Fac. Agr., Kyushu Univ., 48: 65-69

Shimojo, M. 2011 Symmetry in motion in Euler's formula and its breakdown in hyperbolic function and growth function. J. Fac. Agr., Kyushu Univ., 56: 79-81 